\title{
Differential Features of COPD in China
}

Fuqiang Wen, MD, PhD, and Yongchun Shen, MD

Department of Respiratory and Critical Care Medicine, West China Hospital of Sichuan University and Division of Pulmonary Diseases, State Key Laboratory of Biotherapy of China, Chengdu, China

\section{ABSTRACT}

Chronic obstructive pulmonary disease (COPD), characterized by persistent airflow limitation, is a public health problem worldwide. It is a major chronic disease in China, which has the largest population of elderly and smokers in the world, as well as the largest number of COPD patients. The occurrence of COPD is linked to multiple risk factors, including smoking, use of biomass fuel, and air pollution. COPD has a major negative effect on the quality of life, including limitations on the work ability. It increases mortality and leads to a significant use of health-care resources. Much progress has already been made in the prevention and treatment of COPD in China, but early diagnosis using spirometry should become more widespread, and general COPD knowledge among clinicians needs to be improved. This review summarizes the clinical characteristics of COPD in China, as well as current concepts for COPD diagnosis and treatment, and future actions to improve disease management in the country. (BRN Rev. 2017;3:74-85)

Corresponding author: Fuqiang Wen, wenfuqiang@126.com or wenfuqiang.scu@gmail.com

Key words: Burden. China. Chronic obstructive pulmonary disease. Incidence. Mortality.

\section{Correspondence to:}

Fuqiang Wen

Department of Respiratory and Critical Care Medicine

West China Hospital of Sichuan University and Division of Pulmonary Diseases

State Key Laboratory of Biotherapy of China

Received in original form: 13-10-2016

Chengdu 610041, China

E-mail: wenfuqiang@126.com or wenfuqiang.scu@gmail.com 


\section{INTRODUCTION}

Chronic obstructive pulmonary disease (COPD) is a progressive disease involving persistent airflow limitation and chronic airway inflammation. It places a heavy burden on patients and family members, healthcare professionals and society, especially in developing countries $^{1-3}$. COPD has a major negative effect on the quality of life, including limitations on the work ability. It increases mortality and leads to a significant use of health-care resources. Based on projections through 2020, COPD is projected to move from the sixth to the third most frequent cause of mortality worldwide, and to rise from the fourth to the third most frequent cause of morbidity ${ }^{4}$.

As one of the largest developing countries in the world, China is subject to great pressure in concerning COPD. Census data from 2010 indicate a population of 1.33 billion, accounting for nearly $20 \%$ of the entire world's population; approximately 568 million people, $42 \%$ of the Chinese population, is at least 40 years old ${ }^{5}$. Since COPD incidence increases exponentially beyond this age threshold, China faces a particularly heavy burden from COPD, especially since many COPD risk factors are also prevalent in this country, such as cigarette smoking, air pollution, and use of biomass fuel. Additional factors contributing to the long-term COPD burden are late diagnosis of COPD and substandard treatment.

Although the diagnosis, evaluation, and treatment of COPD have advanced in China in recent decades, many challenges remain ${ }^{6}$. This review summarizes the clinical characteristics of Chinese COPD patients, the progress in clinical care so far, and the challenges for the future.

\section{COPD RISK FACTORS IN CHINA}

The Chinese population is exposed to numerous COPD risk factors. Smoking is the most common risk factor for COPD worldwide, and 2010 data suggest approximately 300 million current smokers in China (Fig. 1) ${ }^{7,8}$. In fact, China is regarded as the largest consumer of tobacco in the world9. Passive smoking is also a major problem: among non-smokers aged 15 years and older, approximately 556 million $(72.4 \%)$ are exposed to second-hand smoke, with 292 million (52.5\%) exposed on a daily basis ${ }^{10}$. A study of 500,000 adults aged 30-79 years from 10 regions across mainland China over the period 2004-2008 showed that $7.2 \%$ of men who smoked regularly had airflow limitation, compared to only $5.4 \%$ of never-smokers. In this study, the amount of smoking was significantly associated with the risk of airflow limitation, defined as a pre-bronchodilator ratio of forced expiratory volume in one second over forced vital capacity $\left(\mathrm{FEV}_{1} /\right.$ FVC) below 0.7 and/or below the lower limit of normal for the specific population ${ }^{11}$. In addition, the risk of COPD was associated with self-reported exposure to second-hand smoke at home and work (adjusted odds ratio: 1.48; 95\% CI: $1.18-1.85)^{12}$.

Approximately $60 \%$ of Chinese families use biomass fuel and $31 \%$ use coal for cooking or heating in rural areas, making these factors significant contributors to the risk of COPD in China ${ }^{13}$, particularly in the rural southern part of the country ${ }^{14}$. Risk is also exacerbated by air pollution, dust, physical and chemical contamination, respiratory tract infection, tuberculosis, and poor socioeconomic status, all of which are prevalent in 


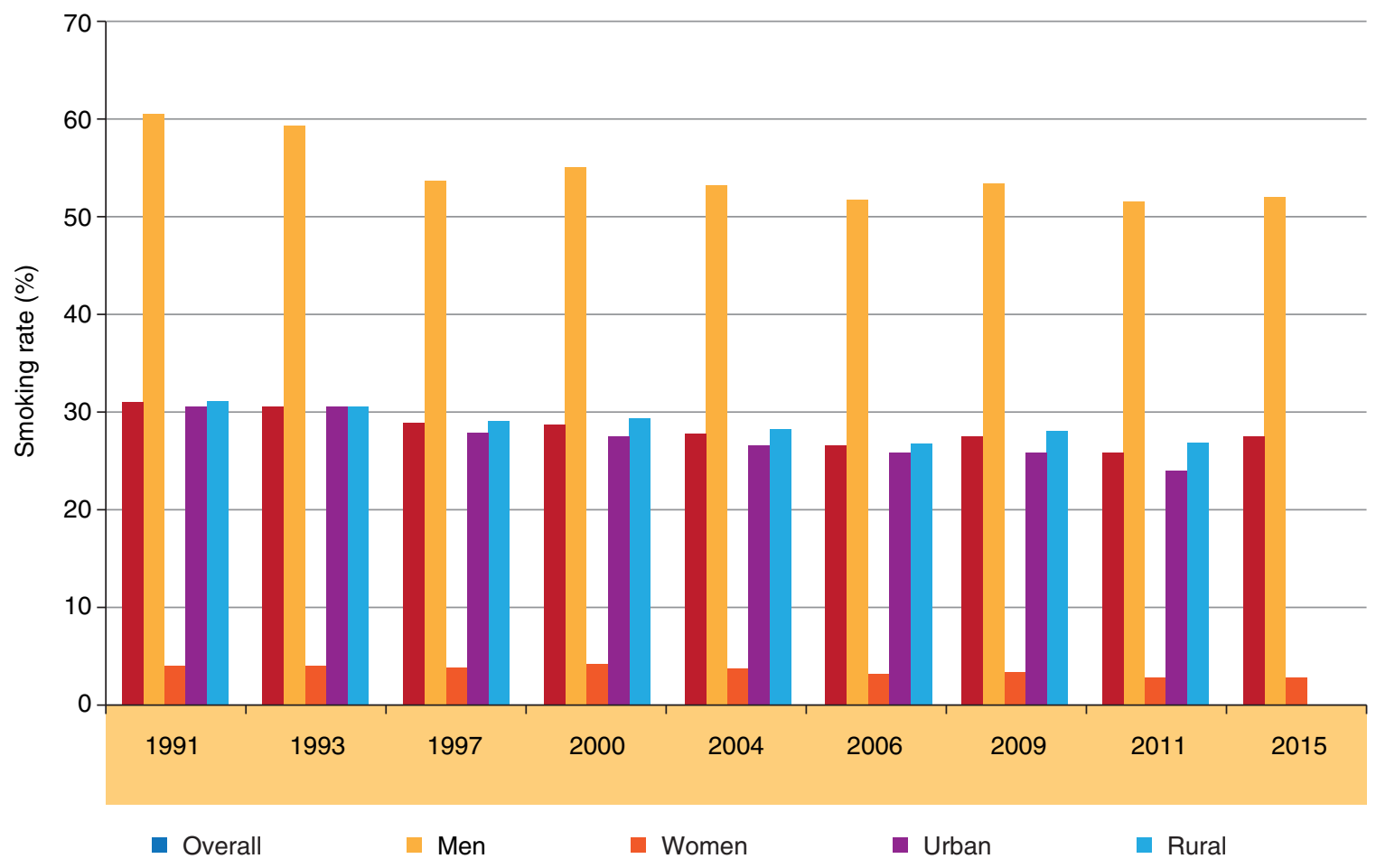

Figure 1. Rate of smoking in China, 1991 to 2015. Trends are shown for men and women living in urban or rural areas.

China ${ }^{15}$. Managing or even reducing such risk factors poses an enormous challenge for the country.

\section{COPD INCIDENCE IN CHINA}

With so many COPD risk factors present in China, it is not surprising that incidence of the disease is high. Incidence across 12 Asian countries, including China, is 6.3\%, considerably higher than the $3.8 \%$ based on data from the World Health Organization (WHO) for the same region $^{16}$. In the Proyecto Latinoamericano de Investigación en Obstrucción Pulmonar (PLATINO) study, performed in five major Latin American cities: São Paulo (Brazil), Santiago
(Chile), Mexico City (Mexico), Montevideo (Uruguay), and Caracas (Venezuela), the incidence of COPD ranged from $7.8 \%$ to $19.7 \% 17$. In the Burden of Obstructive Lung Disease (BOLD) study which was carried out in 12 cities, the mean COPD incidence was $17.3 \%{ }^{18}$. A systematic review has indicated worldwide COPD prevalence of $7.6 \%$ based on 37 studies, and worldwide prevalence of spirometry-confirmed COPD of $8.9 \%$ based on 26 studies $^{19}$. This review also highlighted notable regional differences in the incidence.

Similarly, classical studies of COPD incidence in China, involving over than 1,000 subjects ${ }^{20-47}$, have revealed variations in incidence across provinces and cities (Table 1). 
TABLE 1. Summary of main epidemiologic studies on COPD incidence in China and worldwide

\begin{tabular}{|c|c|c|c|c|c|c|c|}
\hline Author (Ref) & Year & Location & Number & Age & $\begin{array}{l}\text { Sampling } \\
\text { method }\end{array}$ & $\begin{array}{l}\text { COPD diagnosis } \\
\text { method }\end{array}$ & $\begin{array}{l}\text { COPD } \\
\text { incidence } \\
(\%)\end{array}$ \\
\hline Ruan et al. ${ }^{35}$ & 2000 & Jiangsu & 16,813 & $\geq 35$ & C & Self-report & 3.5 \\
\hline Yao et al. ${ }^{20}$ & 2005 & Beijing & 1,624 & $\geq 40$ & M & Lung function tests & 9.1 \\
\hline Liu et al. ${ }^{24}$ & 2005 & Guangdong & 3,286 & $\geq 40$ & M & Lung function tests & 9.4 \\
\hline Wang et al. ${ }^{25}$ & 2005 & Guangdong & 1,498 & $\geq 40$ & C & Lung function tests & 12.0 \\
\hline Xu et al. ${ }^{34}$ & 2005 & Jiangsu & 29,319 & $\geq 35$ & M & Self-report & 5.9 \\
\hline Ma et al. ${ }^{41}$ & 2005 & Shanghai & 1,214 & $\geq 60$ & $S$ & Lung function tests & 12.1 \\
\hline Qiu et al. ${ }^{45}$ & 2005 & Yunnan & 5,791 & $\geq 15$ & M & Lung function tests & 2.0 \\
\hline Weng et al. ${ }^{47}$ & 2005 & Zhejiang & 1,209 & $\geq 60$ & C & Lung function tests & 6.5 \\
\hline Weng et al. ${ }^{26}$ & 2006 & Guangdong & 1,100 & $\geq 40$ & C & Lung function tests & 12.6 \\
\hline Zhong et al. ${ }^{21}$ & 2007 & $\begin{array}{l}\text { Beijing, Tianjing, Liaoning, Shanghai,Guodong, } \\
\text { Shanxi,Chongqin }\end{array}$ & 20,245 & $\geq 40$ & M & Lung function tests & 8.2 \\
\hline Jiang et al..$^{33}$ & 2007 & Hubei & 1,883 & $\geq 40$ & M & Lung function tests & 9.9 \\
\hline Shan et al. ${ }^{42}$ & 2007 & Tianjin & 3,008 & $\geq 40$ & C & Lung function tests & 9.6 \\
\hline Chen et al. ${ }^{27}$ & 2008 & Guangdong & 1,368 & $\geq 40$ & C & Lung function tests & 7.0 \\
\hline Li et al. ${ }^{22}$ & 2009 & Chongqin & 1,518 & $\geq 40$ & $\mathrm{M}$ & Lung function tests & 12.8 \\
\hline Yu et al. ${ }^{32}$ & 2009 & Hebei & 1,948 & $\geq 40$ & M & Lung function tests & 10.7 \\
\hline Cai et al. ${ }^{44}$ & 2009 & Yunnan & 6,006 & $\geq 45$ & M & Self-report & 6.7 \\
\hline Weng et al..$^{23}$ & 2011 & Chongqin & 2,024 & $\geq 40$ & M & Lung function tests & 7.9 \\
\hline Fu et al..$^{30}$ & 2011 & Hunan & 1,000 & $\geq 40$ & C & Lung function tests & 9.1 \\
\hline Li et al. ${ }^{39}$ & 2011 & Shandong & 4,047 & $\geq 40$ & M & Lung function tests & 8.6 \\
\hline Wang et al. ${ }^{40}$ & 2011 & Shandong & 2,055 & $\geq 40$ & M & Lung function tests & 7.6 \\
\hline Wang et al. ${ }^{46}$ & 2011 & Zhejiang & 1,467 & $\geq 55$ & C & Lung function tests & 16.3 \\
\hline Cai et al..$^{28}$ & 2012 & Guangdong & 1,019 & $\geq 40$ & C & Lung function tests & 10.2 \\
\hline Tang et al. ${ }^{29}$ & 2012 & Helongjiang & 1,509 & $\geq 40$ & C & Lung function tests & 11.3 \\
\hline Hong et al. ${ }^{31}$ & 2012 & Hunan & 8,269 & $\geq 15$ & C & Lung function tests & 5.1 \\
\hline Hou et al. ${ }^{36}$ & 2012 & Liaoning & 2,194 & $\geq 35$ & C & Lung function tests & 5.1 \\
\hline Qiu et al. ${ }^{38}$ & 2013 & Ningxia & 4,626 & $\geq 40$ & M & Lung function tests & 8.9 \\
\hline Zhu et al. ${ }^{43}$ & 2014 & Xinjiang & 2,874 & $\geq 35$ & C & Lung function tests & 7.5 \\
\hline Liu et al. ${ }^{37}$ & 2015 & Liaoning & 5,420 & & C & Lung function tests & 17.5 \\
\hline Menezes et al. ${ }^{17}$ & 2005 & $\begin{array}{l}\text { São Paulo, Santiago, Mexico City, } \\
\text { Montevideo, Caracas. }\end{array}$ & 5,571 & $\geq 40$ & M & Lung function tests & 14.3 \\
\hline Buist et al. ${ }^{18}$ & 2007 & $\begin{array}{l}\text { Guangzhou, Adana, Salzburg, Cape Town, } \\
\text { Reykjavik, Hannover, Krakow, Bergen, } \\
\text { Vancouver, Lexington, Manila, Sydney }\end{array}$ & 8,775 & $\geq 40$ & M & Lung function tests & 17.3 \\
\hline
\end{tabular}

C: cluster random sampling; COPD: chronic obstructive pulmonary disease; M: multi-stage cluster random sampling. 
One particularly large, population-based, crosssectional survey of COPD involving 20,245 respondents from Beijing, Tianjin, Liaoning, Shanghai, Guodong, Shanxi, and Chongqing found overall prevalence of spirometry-confirmed COPD to be $8.2 \%$ overall, $12.4 \%$ in men and $5.1 \%$ in women (corresponding to nearly 43 million people) for the period 2002-0421. COPD incidence in that study varied across the areas and was linked to specific occupations. For example, a cross-sectional study of greenhouse farmers in Northeast China found an overall COPD prevalence of $17.5 \%{ }^{37}$.

A recent meta-analysis of 30 studies covering 18 Chinese provinces and cities for the period 1990-2014 indicated a COPD incidence of 9.9\% overall, $13.0 \%$ of men and $5.8 \%$ of women aged 40 or older. The incidence increased with age group, from $3.2 \%$ among those aged $40-49$ years to $20.3 \%$ among those aged 70 or older. Over the last 20 years, COPD prevalence has gradually increased among those aged 40 or older ${ }^{48}$. Thus, as the Chinese population ages, more and more will be diagnosed with COPD in the coming years. Indeed, nationwide Chinese data presented at the 2016 Annual Conference of the European Respiratory Society (ERS) suggest that COPD incidence is more than $14 \%$ among those older than 40 and $8 \%$ among those older than $20^{49}$. This means that China has the world's highest incidence of COPD. Dealing with this epidemic poses enormous challenges for the country.

\section{COPD-RELATED MORTALITY IN CHINA}

In 2010, an estimated 328 million people worldwide had COPD, being the third leading cause of death. Although age-standardized rates of COPD-related death have decreased by $43.3 \%$ in the past two decades, falling from 77.4 per 100,000 in 1990 to 43.8 per 100,000 in $2010^{50}$, COPD-related mortality remains high in China (Fig. 2). In 2004-2005, the crude death rate in the country was 82.32 per 100,000 and the standardized death rate was 71.18 per 100,000. COPD is the third-leading cause of mortality in China, accounting for 934,000 deaths in 2010 and 910,809 deaths in 2013, corresponding to one COPD-related death approximately every 2 minutes ${ }^{51,52}$.

COPD accounts for as many as $81 \%$ of deaths in China related to respiratory disease $\mathrm{e}^{53}$. The burden of COPD-related deaths may be heavier in western rural areas than in other rural areas $^{54}$ : the crude rate of COPD-related deaths in western rural areas is as high as 122.04 per 100,000. COPD-related mortality is much higher in China than elsewhere in the Asia-Pacific region, where it is reported to be 64-92 per 100,000 men and 21-35 per 100,000 women ${ }^{55}$.

\section{COPD BURDEN IN CHINA}

COPD places a high economic burden on countries. Direct costs in the European Union are 38.6 billion euros, accounting for $56 \%$ of the costs of all respiratory diseases. In the United States, direct costs are $\$ 29.5$ billion and indirect costs are $\$ 20.4$ billion $^{56,57}$. In China, the costs associated with COPD are even higher and they pose a severe burden on patients and their families.

A cross-sectional survey in 2006 based on interviews with 723 COPD outpatients in the large cities of Beijing, Shanghai, Guangzhou, 


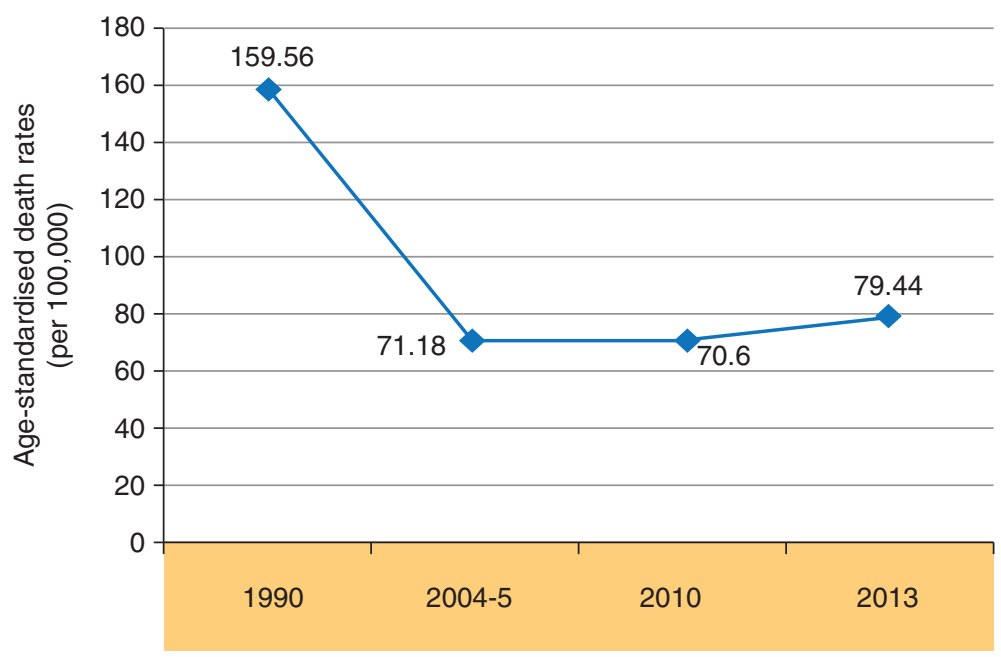

Figure 2. Age-standardized rate of chronic obstructive pulmonary disease (COPD)-related deaths (per 100,000) in China. Data were taken from references $47,49-50$. When data were conflicting, only the most recent data were used.

Chengdu, Xi'an, and Shenyang found the average annual direct medical expenses to be $\$ 1,732.24$ per patient. Indirect costs, for example, for nutritional support, transportation, and end-of-life care were approximately $\$ 231.6$ per patient, accounting for $40 \%$ of an average family's total income $(\$ 4,849.8)^{58}$.

COPD costs correlate strongly with disease severity, and a major contributor to these costs is hospitalization ${ }^{59}$. A survey based on 83 third-tier hospitals in 17 provinces and cities of China revealed that for $97.5 \%$ of patients, the cost of a monthly supply of medicines was greater than their monthly wage; the average annual economic burden of disease was 20107.56 Renmibi (RMB) per patient ${ }^{60}$. In general, the affordability of COPD drugs is quite low in third-tier hospitals, with annual medication costs for inpatients rising as high as $628440.6 \mathrm{RMB}$ per patient ${ }^{59,61}$. This highlights the need to make COPD drugs more affordable and to protect patients from economic risk associated with their disease.

COPD burden tends to be underestimated because of premature mortality of patients and the loss of work productivity of patients and family members. COPD seriously affects the quality of life of COPD patients, largely due to disease-related changes in dyspnoea, comorbidities and loss of body mass index ${ }^{62}$. Overall disease burden in terms of disability-adjusted life years (DALYs) is predicted to double over the next 2.5 decades. By then, COPD is expected to move from position 13 to position 7 in terms of DALYs. In 2010, COPD was the fifth major cause of years lived with disability in China ${ }^{63}$. In this same year in China, COPD-related DALYs were 16,598 million person-years; years of life lost due to premature mortality, 12,946 million person-years; and, years lived with disability, 3,652 million person-years ${ }^{64}$. This burden affects patients 
TABLE 2. Percentage of chronic obstructive pulmonary disease (COPD) patients received spirometry examination before diagnosis

\begin{tabular}{|l|c|c|c|}
\hline Study & Number of COPD patients & $\begin{array}{c}\text { Number of patients with } \\
\text { spirometry performed before } \\
\text { diagnosis }\end{array}$ & \begin{tabular}{c} 
Percentage \\
\hline Zhong et al. ${ }^{21}$
\end{tabular} \\
\hline Weng et al. ${ }^{23}$ & 1,668 & 108 & 6.50 \\
\hline Liu et al. ${ }^{24}$ & 160 & 39 & 24.38 \\
\hline Cai et al. ${ }^{28}$ & 310 & 26 & 8.39 \\
\hline Lin et al. ${ }^{66}$ & 105 & 9 & 8.57 \\
\hline Lv et al. ${ }^{67}$ & 283 & 33 & 11.66 \\
\hline Tang et al. ${ }^{68}$ & 145 & 10 & 6.90 \\
\hline
\end{tabular}

and family members alike: $36 \%$ of COPD patients reported losing an average of 17 working days over the preceding 12 months because of their disease, and $17 \%$ of patients' family members reported losing an average of 14 working days due to taking care of patients $^{58}$.

Decreased quality of life related with COPD may be associated with higher medical costs. A cross-sectional survey of 678 COPD patients found poorer quality of life to be significantly associated with higher direct medical costs. This may be important for healthcare policymakers to take into account ${ }^{65}$.

\section{LOW RATE OF SPIROMETRY-BASED COPD DIAGNOSIS}

COPD diagnosis occurs too late for many patients in China, and treatment is often insufficient. Spirometry is the gold standard to detect airflow limitation and diagnose COPD according to the Global Initiative for Chronic Obstructive Lung Disease (GOLD) ${ }^{1}$, but it is not often used in China to diagnose the disease
(Table 2) $21,23,24,28,66-68$. This can lead to a disturbingly high rate of misdiagnosis: one study of 185 patients diagnosed with "COPD" without performing lung function tests showed that only 75 truly had COPD based on spirometry, while another 47 had a normal lung function based on this GOLD standard ${ }^{69}$. A survey in Beijing involving 708 subjects revealed that only $8.33 \%$ of the COPD patients received spirometry examination in rural areas ${ }^{70}$. A large population-based survey found that only $6.5 \%$ of COPD patients were tested with spirometry ${ }^{21}$. A China Kadoorie Biobank report of 512,891 adults from 10 regions across China found that only $11.2 \%$ of diagnoses of airflow limitation made in the period 2004-08 were correct, based on spirometry findings ${ }^{71}$. The proportion of cases of airflow limitation that went undiagnosed was greater among women, younger individuals, those with lower household income, those with fewer chronic respiratory symptoms, and current regular smokers ${ }^{71}$.

The use of spirometry may significantly improve timely diagnosis of COPD, but clinicians in the country often do not regard it as critical for accurate diagnosis. A cross-sectional 
survey of COPD knowledge among physicians at tertiary hospitals in northern China revealed that only $59.0 \%$ recognized the importance of spirometry for COPD diagnosis ${ }^{72}$. A survey of physicians at basic hospital in Nanjing found them to prefer chest X-ray to lung function tests as the first choice for COPD diagnosis $^{73}$. Of course, failure to use spirometry to diagnose COPD can reflect not only a lack of knowledge but also a lack of equipment and funding, especially in primary care settings.

Another challenge to the timely diagnosis of COPD in China is the fact that many Chinese patients are asymptomatic. In one study of 25,627 subjects, 1,668 were diagnosed with COPD, of whom 589 (35.3\%) were asymptomatic $^{74}$. And in the PLATINO study performed in São Paulo, the undiagnosed group of COPD patients had a lower proportion of subjects with respiratory symptoms than the previously diagnosed patients ${ }^{75}$. Both the PLATINO and BOLD studies highlight that spirometry can help in the diagnosis of COPD at a stage when treatment will lead to better outcomes and improved quality of life ${ }^{76}$. Without spirometry examination, clinicians may tend to over-diagnose COPD based only on clinical symptoms, and to under-diagnose it in asymptomatic individuals.

\section{LOW RATE OF STANDARDIZED COPD TREATMENT}

Physicians' knowledge on COPD can strongly influence treatment efficacy, and awareness of COPD treatment standards in China is inconsistent. A survey among 372 physicians found that COPD knowledge was not satisfactory at district and community hospitals ${ }^{77}$. While such knowledge levels have improved among physicians in large cities, knowledge of long-term COPD interventions such as pharmacotherapy remains unsatisfactory ${ }^{78}$. A survey among 700 COPD patients treated in China found that $61 \%$ received mucoactive drugs as first-line pharmacotherapy for $\mathrm{COPD}^{79}$, even though GOLD standards recommend bronchodilators such as $\beta 2$-agonists, anticholinergic agents, and aminophylline as COPD drugs. In fact, patients with moderate or severe COPD are prescribed mucoactive drugs in as many as $87 \%$ of newly diagnosed cases, and in as many as $80 \%$ of follow-up patients ${ }^{78}$. Even when Chinese physicians prescribe bronchodilators, more than $50 \%$ choose short-acting bronchodilators $^{79}$. Moreover, even though mucoactive therapy is considered of great importance in China to treat patients with $\mathrm{COPD}^{80}$, this questionable recommendation principle is not always followed in clinical practice.

A similar gap between international standards and Chinese practice occurs in the management of patients with stable COPD. Although GOLD standards recommend maintainance therapy for such patients, as many as $15 \%$ of physicians at basic hospitals think that no active treatment is necessary ${ }^{73}$. That said, the five most common interventions in northeast China are smoke cessation, antibiotic use, inhaled corticosteroids, long- acting anti-cholinergics and oxygen ${ }^{72}$. There is a long way to go before COPD patients can benefit from standard treatment in China.

\section{PROSPECTS FOR COPD IN CHINA}

China has already made substantial progress in improving diagnosis and treatment of 


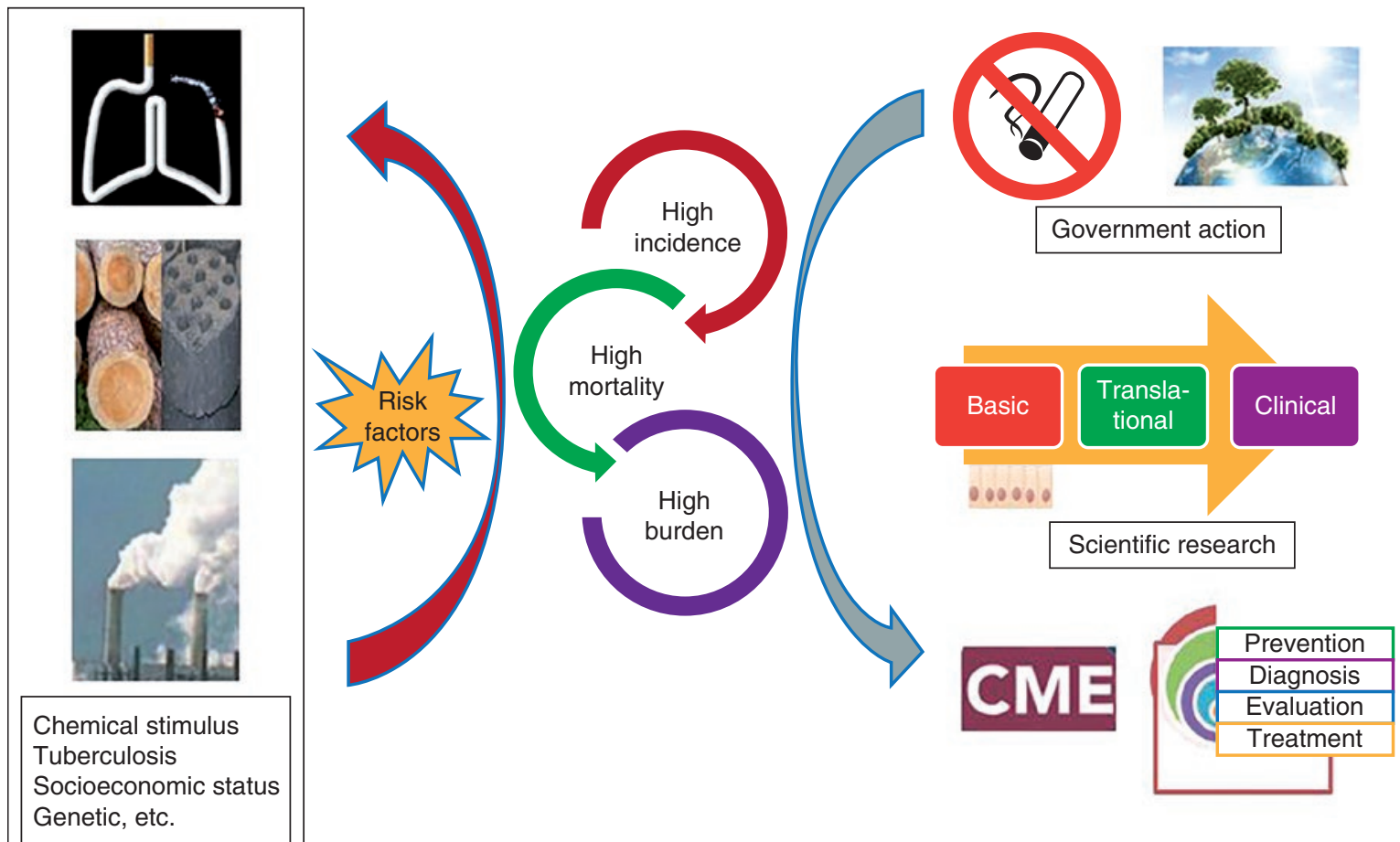

Figure 3. Challenges and recommendations for diagnosing and treating chronic obstructive pulmonary disease (COPD) in China. CME: continuous medical education.

COPD, and the latest national plan on the Prevention and Treatment of Chronic Diseases pledges to bring the incidence of COPD in those older than 40 below $8 \%{ }^{81}$. The Chinese government has taken steps to reduce many COPD risk factors. For example, advertising laws have been revised to prohibit cigarette advertising, and the tax on tobacco has been increased. In 18 major cities, China has set up local tobacco control laws to forbid smoking in public places, especially hospitals and schools ${ }^{82}$. Guidelines to help individuals quit smoking have been published ${ }^{83}$. A prospective cohort study spanning 9 years has provided strong evidence that cooking with clean fuels such as biogas rather than biomass and improving kitchen ventilation (by providing support and instruction for improving biomass stoves or installing exhaust fans) are associated with a smaller decline in $\mathrm{FEV}_{1}$ and lower risk of $\mathrm{COPD}^{84}$.

Both the Chinese government and clinical professionals are stepping up to increase COPD knowledge among physicians and to encourage the use of spirometry for early diagnosis of the disease. The Chinese National Health and Family Planning Commission issued a "China Health Knowledge Dissemination and Incentive Plan" focusing on COPD management (COPD 2012-2013). The People's Medical Publishing House has organized a training program to increase the knowledge of 5,000-6,000 physicians in primary hospitals 
about COPD prevention, diagnosis, and treatment ${ }^{85}$. COPD has been included in "specific clinics" in most Chinese provinces, and Local Social Security Bureaus in urban and rural areas cover some of the fees related to COPD drugs and exams.

Efforts to expand research and clinical translation of new knowledge and treatment for COPD and other diseases are funded through the National Ministry of Science and Technology of China, which has launched several grant programs such as "Precision Medicine" and "Major Chronic Non-infectious Diseases". COPD-related projects alone received more than 60 million RMB of funding in $2016^{86}$. These projects cover COPD pathogenesis, phenotypes, treatment, and management of acute exacerbations. Figure 3 summarizes the current challenges and actions for COPD in China.

These recent developments speak of the overall commitment of the Chinese government, researchers and clinicians to improve COPD diagnosis and treatment around the country. While many challenges stand in the way, China is poised to make impressive headway in COPD patient care in the years to come.

\section{ACKNOWLEDGMENTS}

This work was supported by the National Key Technology Study and Development Program of the Ministry of Science and Technology of China (2014BA108B04), the National Key Research and Development Program in China (2016YFC0903600, 2016YFC1304500), and the Science and Technology Pillar Program of the Department of Science and Technology of Sichuan province (2015SZ0151).

\section{CONFLICT OF INTEREST}

Professor Fuqiang Wen and Dr. Yongchun Shen have nothing to disclose.

\section{REFERENCES}

1. Vogelmeier C, Agusti A, Anzueto A et al. Global strategy for the diagnosis, management, and prevention of Chronic Obstructive Pulmonary Disease (2017 Report) 2017 [Available from: http:/ / goldcopd.org/ gold-2017-global-strategy-diagnosis-management-prevention-copd/].

2. Martinez FD. Early-Life Origins of Chronic Obstructive Pulmonary Disease N Engl J Med. 2016;375:871-8.

3. Rennard SI, Drummond MB. Early chronic obstructive pulmonary disease: definition, assessment, and prevention. Lancet. 2015;385:1778-88.

4. Murray CJ, Lopez AD. Alternative projections of mortality and disability by cause 1990-2020: Global Burden of Disease Study. Lancet. 1997;349:1498-504.

5. Tabulation on the population census of the People's Republic of China. http://www.stats.gov.cn/tjsj/pcsj/rkpc/6rp/indexch.htm, Accessed September 1, 2016.

6. Guan WJ, Ran PX, Zhong NS. Prevention and management of COPD in China: successes and major challenges. Lancet Respir Med. 2016;4:428-30.

7. Li S, Meng L, Chiolero A, Ma C, Xi B. Trends in smoking prevalence and attributable mortality in China, 1991-2011. Prev Med. 2016;93:82-7.

8. Yang Y, Nan Y, Tu M, Wang J. Major finding of 2015 China adults tobacco survey (Chinese). Chin J Health Manage. 2016;10:85-7.

9. Li Q, Hsia J, Yang G. Prevalence of smoking in China in 2010. N Engl J Med. 2011; 364:2469-70. doi: 10.1056/NEJMc1102459.

10. Xiao L, Yang Y, Li Q, Wang CX, Yang GH. Population-based survey of secondhand smoke exposure in China. Biomed Environ Sci. 2010; 23:430-6.

11. Kurmi OP, Li L, Wang J et al. COPD and its association with smoking in the Mainland China: a cross-sectional analysis of 0.5 million men and women from ten diverse areas. Int J Chron Obstruct Pulmon Dis. 2015;10: 655-65.

12. Yin $\mathrm{P}$, Jiang $\mathrm{CQ}$, Cheng $\mathrm{KK}$ et al. Passive smoking exposure and risk of COPD among adults in China: the Guangzhou Biobank Cohort Study Lancet. 2007;370:751-7.

13. Mestl HE, Aunan K, Seip HM et al. Urban and rural exposure to indoor air pollution from domestic biomass and coal burning across China. Sci Total Environ. 2007;377:12-26.

14. Liu S, Zhou $Y$, Wang $X$ et al. Biomass fuels are the probable risk factor for chronic obstructive pulmonary disease in rural South China. Thorax. 2007, 62:889-97.

15. Zhou Y, Chen R. Risk factors and intervention for chronic obstructive pulmonary disease in China. Respirology. 2013;18 Suppl 3:4-9.

16. Regional COPD Working Group. COPD prevalence in 12 Asia-Pacific countries and regions: projections based on the COPD prevalence estimation model. Respirology. 2003;8:192-8.

17. Menezes AM, Perez-Padilla R, Jardim JR et al. Chronic obstructive pulmonary disease in five Latin American cities (the PLATINO study): a prevalence study. Lancet. 2005;366:1875-81.

18. Buist AS, McBurnie MA, Vollmer WM et al. International variation in the prevalence of COPD (the BOLD Study): a population-based prevalence study. Lancet. 2007;370:741-50.

19. Halbert RJ, Natoli JL, Gano A, Badamgarav E, Buist AS, Mannino DM. Global burden of COPD: systematic review and meta-analysis. Eur Respir J. 2006;28:523-32.

20. Yao W, Zhu H, Shen $\mathrm{N}$ et al. Epidemiological data of chronic obstructive pulmonary disease in Yanqing County in Beijing (Chinese). Beijing Da Xue Xue Bao. 2005;37:121-5. 
21. Zhong N, Wang C, Yao W et al. Prevalence of chronic obstructive pulmonary disease in China: a large, population-based survey. Am J Respir Crit Care Med. 2007;176:753-60.

22. Li Q, Liao X, Zhang Q. Epidemiological sampling survey on chronic obstructive pulmonary disease in urban area of Chongqing (Chinese). Chin J Respir Crit Care Med. 2009;8:12-5.

23. Weng HA, Lai FH, He ZJ et al. Prevalence of chronic obstructive pulmonary disease in community residents of urban Chongqing (Chinese). Chin J Public Health. 2011;7(11):1393-6

24. Liu SM, Wang XP, Wang DL et al. Epidemiologic analysis of COPD in Guangdong province (Chinese). Zhonghua Yi Xue Za Zhi. 2005;85:747-52.

25. Wang X, Zhou Y, Zeng X et al. Study on the prevalence rate of chronic obstructive pulmonary disease in northern part of Guangdong province (Chinese). Zhonghua Liu Xing Bing Xue Za Zhi. 2005;26:211-3.

26. Weng JL, Zheng YS, Wang WL et al. Survey on the prevalence of chronic obstructive pulmonary diseases in the area of Shantou (Chinese). Hainan Med J. 2006;17:122-3.

27. Chen $\mathrm{H}, \mathrm{Su} \mathrm{W}$, Chen $X$. Epidemiologic survey and risk factors analysis of COPD in People aged 40ys or older in rural areas of Lianjiang, Guangdong (Chinese). J Guangdong Med. 2008;26:560-4

28. Cai XZ, Lai SH, He CS. Analysis on the prevalence and prevention of COPD in the rural area in Dongguan (Chinese). Int Med Health Guid News. 2012;18:151-3.

29. Tang WL, Yu BQ, Zhang XF et al. Epidemiological survey of chronic obstructive pulmonary disease in Harbin rural areas (Chinese). J Clin Intern Med. 2012;29:817-9.

30. Fu X, Hu H, Hu MF. Epidemiological sampling survey on chronic obstructive pulmonary disease in urban area of Chenzhou city (Chinese). J Clin Pulm Med. 2011;16:184-5.

31. Hong XQ, Dai AG, Kong CC et al. Epidemic situation and risk factors analysis of COPD in partial areas of Hunan province (Chinese). Chin J Gero. 2012;32:795-7.

32. Yu CL, Zhao CM, Li XX. Survey on prevalence of chronic obstructive pulmonary disease in rural areas of Tangshan (Chinese). C1in Focus, 2009:24:1857-60.

33. Jiang RG, Luo DS, Huang CP. Study on the prevalence rate and risk factors of chronic obstructive pulmonary disease in rural community population in Hubei province (Chinese). Chin J Epidemi. 2007;28:976-9.

34. Xu F, Yin X, Zhang M, Shen H, Lu L, Xu Y. Prevalence of physician-diagnosed COPD and its association with smoking among urban and rural residents in regional mainland China. Chest. 2005;128:2818-23.

35. Ruan SR. The analysis on the prevalence and risk factors of chronic obstructive pulmonary diseases in the city of Liyang (Chinese). Jiangsu Health Care. 2000;2:202-3.

36. Hou G, Yin Y, Su LL, et al. Prevalence rate and risk factors of chronic obstructive pulmonary disease in residents aged 35 years or older in communities of Shenyang city (Chinese). J Chin Gen Pract. 2012;15:1831-1833.

37. Liu S, Ren Y, Wen D et al. Prevalence and risk factors for COPD in greenhouse farmers: a large, cross-sectional survey of 5,880 farmers from northeast China. Int J Chron Obstruct Pulmon Dis. 2015;10:2097-108.

38. Qiu J, Zhang YN, Chen J et al. Prevalence of chronic obstructive pulmonary disease in Ningxia Hui Autonomous Region of China (Chinese). ZhonghuaJie He He Hu Xi ZaZhi. 2013;36:265-8.

39. Li ZJ, Zhang SZ, Kong XT. A prevalence survey on chronic obstructive pulmonary disease among people aged over 40 years in zaozhuang rural area of Shandong province (Chinese). Chin J Pract Med. 2011;38:19-21.

40. Wang C, Ma DD, Xiao W et al. Epidemiological status and related risk factors of COPD in urban residents in Jinan. Shandong Da Xue Xue Bao (Health Science). 2011;49:128-32.

41. Ma R, Cheng QJ, Yap D et al. Epidemiological survey of chronic obstructive pulmonary disease in the eiders in Shanghai (Chinese). J Shanghai Sec Med Univ. 2005;25:521-4

42. Shan S, Chen B. Epidemiology Investigation of chronic obstructive pulmonary disease in city and country of Tianjin (Chinese). Tianjin Yi Yao. 2007;35: 488-90.
43. Zhu LL, Fang MQ, Zhu J et al. Correlation study of body mass index with morbidity rate of chronic obstructive pulmonary disease in parts of Xinjiang (Chinese). Clin Med. 2014;34:1-3.

44. Cai L, Zhao KY, Tang PF. Analysis on burden of chronic obstructive pulmonary disease in rural Kunming (Chinese). Chin J Prev Contr Chron Dis. 2009;17:80-1.

45. Qiu J, Zhang MR, Gong HQ et al. An analysis on epidemiological status and risk factors of COPD in Kunming plateau district (Chinese). Pract Prev Med. 2005;12:52-3.

46. Wang YY, Li B, Wang L et al. Prevalence survey on elderly patients with chronic obstructive pulmonary disease(Chinese). Chin Mod Doctor. 2011; 49:19-21.

47. Weng HX, Lin J, Yang PL et al. Relationship between smoking and the incidence of COPD in the Wenzhou elderly (Chinese). Pract Prev Med. 2005;12:776-7.

48. Bao H, Fang L, Wang L. Prevalence of chronic obstructive pulmonary disease among community population aged $\geq 40$ in China: a Meta-analysis on studies published between 1990 and 2014 (Chinese). Zhonghua Liu Xing Bing Xue Za Zhi. 2016;37:119-24.

49. Wang C. The prevalence of COPD in China: data from the latest national survey. 2016 ERS congress. http://www.ers-education.org/events/international-congress/london-2016.aspx?idParent=151488

50. Lozano R, Naghavi M, Foreman K et al. Global and regional mortality from 235 causes of death for 20 age groups in 1990 and 2010: a systematic analysis for the Global Burden of Disease Study 2010. Lancet. 2012;380:2095-128.

51. Yang G, Wang Y, Zeng Y et al. Rapid health transition in China, 1990-2010: findings from the Global Burden of Disease Study 2010. Lancet. 2013;381: 1987-2015.

52. Zhou M, Wang H, Zhu J et al. Cause-specific mortality for 240 causes in China during 1990-2013: a systematic subnational analysis for the Global Burden of Disease Study 2013. Lancet. 2016;387:251-72.

53. Hu N, Huang Z, Jiang Y, Wu F. Mortality and death cause proportion of respiratory diseases in China, 2004-2005 (Chinese). Chin J Prev Med. 2010; 44:298-302.

54. Shi X, Hu N, Li X, Huang Z, Jiang Y, Zhao W. Disease burden of chronic obstructive pulmonary diseases in west rural areas if China, 2004-2005 (Chinese). Chin J Prev Med. 2011;45:68-72.

55. Tan WC, Seale P, Ip M et al. Trends in COPD mortality and hospitalizations in countries and regions of Asia-Pacific. Respirology. 2009;14:90-7.

56. European Respiratory Society. European Lung White Book: Huddersfield European Respiratory Society Journals, Ltd, 2003.

57. National Heart, Lung, and Blood Institute. Morbidity and mortality chartbook on cardiovascular, lung and blood diseases. Bethesda, Maryland: US Department of Health and Human Services, Public Health Service, National Institutes of Health. Accessed at: http://www.nhlbi.nih.gov/resources / docs/cht-book.htk;2009.

58. He QY, Zhou X , Xie CM , Liang Z, Chen P, Wu C. Impact of chronic obstructive pulmonary disease on quality of life and economic burden in Chinese urban areas (Chinese). Zhonghua Jie He He Hu Xi Za Zhi. 2009;32:253-7.

59. Zhu M, Cai B. Economic evaluation on chronic obstructive pulmonary disease (Chinese). Guo Ji Hu Xi Za Zhi. 2008;28:1333-6.

60. Li J, Feng R, Cui Y, Liu S, Zeng Zhao, Y, Wang X. Analysis on the affordability and economic risk for using medicine to treat patients with chronic obstructive pulmonary diseases in Tier 3 hospitals in China (Chinese). Chin Heal Economics. 2015;33:66-8.

61. Guo Z, Wang X. Impact of chronic obstructive pulmonary disease hospitalization on economic burden in Chinese (Chinese). Zhong Guo Wei Shen Tong Ji. 2010;27:345-347,350.

62. Zhou YM, Wang C, Yao WZ et al. The quality of life of patients with chronic obstructive pulmonary disease and correlated factors (Chinese). Zhonghua Jie He He Hu Xi Za Zhi. 2009;32:248-52.

63. Vos T, Flaxman AD, Naghavi $\mathrm{M}$ et al. Years lived with disability (YLDs) for 1160 sequelae of 289 diseases and injuries 1990-2010: a systematic analysis for the Global Burden of Disease Study 2010. Lancet. 2012;380:2163-96. 
64. Yin P, Wang L, Liu S et al. The disease burden of chronic obstructive pulmonary disease among people aged over 15 years in 1990 and 2010 in China (Chinese). Zhonghua Yu Fang Yi Xue Za Zhi. 2015;49:334-8.

65. Wu M, Zhao Q, Chen Y, Fu C, Xu B. Quality of life and its association with direct medical costs for COPD in urban China. Health Qual Life Outcomes. 2015;13:57.

66. Lin J, Yuan J, Wang D, Wu H. A survey of clinical presentation and pulmonary function in out-patients with chronic obstructive pulmonary disease (Chinese). Chin J Respir Crit Care Med. 2004;3:185-8.

67. Lv X, Chen W, Liu J et al. An epidemiological survey and risk factors analysis of chronic obstructive pulmonary diseases in Jiaxing City of Zhejiang province (Chinese). Chin J Evid-based Med. 2015;15:628-32.

68. Tan J, Yang M, Meng D, Xin J, Zhou Q, Tao X. The risk factors and management for chronic obstructive pulmonary disease in community residents of Hankou, Wuhan (Chinese). J Clin Intern Med. 2016;33:318-22.

69. Li XF, Zhang FY, Hang JQ. Pulmonary function tests in diagnosis of chronic obstructive pulmonary disease (Chinese). Clin Focus. 2009;24:387-9.

70. Hu XL, Hou CL, Rui T et al. Underuse of spirometry in rural community introduced the missed diagnosis of chronic obstructive pulmonary disease (Chinese). Zhonghua Quan Ke Yi Xue Za Zhi. 2015;14:250-5.

71. Kurmi OP, Li L, Smith M, Augustyn M et al. Regional variations in the prevalence and misdiagnosis of air flow obstruction in China: baseline results from a prospective cohort of the China Kadoorie Biobank (CKB). BMJ Open Respir Res. 2014;1:e000025.

72. Zhou XM, Wu C, Zhao L et al. A cross-sectional survey of the knowledge on chronic obstructive pulmonary disease in physicians of tertiary hospitals in Northern China (Chinese). Zhonghua Nei Ke Za Zhi. 2016;55:717-20.

73. Xie H, Tao Z, Tang SW, Shen HB, Huang R. Investigation of physicians' cognitive level and the status of treatment about COPD in basic hospitals in Nanjing (Chinese). Shiyong Lao Nian Yi Xue. 20011;25:457-460.

74. Lu M, Yao WZ, Zhong NS et al. Asymptomatic patients of chronic obstructive pulmonary disease in China. Chin Med J (Engl). 2010;123:1494-9.
75. Nascimento OA, Camelier A, Rosa FW et al. Chronic obstructive pulmonary disease is underdiagnosed and undertreated in São Paulo (Brazil): results of the PLATINO study. Braz J Med Biol Res. 2007;40:887-95.

76. Lamprecht B, Soriano JB, Studnicka M et al. Determinants of underdiagnosis of COPD in national and international surveys. Chest. 2015;148:971-85.

77. Zhang R, He Q. Awareness of knowledge of COPD by doctors in district and community hospitals (Chinese). China J Prev Contr Chron Dis. 2009 17:61-3.

78. He Q, Zhou X, Xie C et al. Knowledge level about prevention and treatment of COPD: A cross-sectional survey in pulmonary physicians (Chinese) Zhongguo Hu Xi Yu Wei Zhong Jian Hu Za Zhi. 2009;8:117-21.

79. He Q, Zhou X, Xie C et al. The investigation of the treatment conditions in stable COPD patients in partial cities of China (Chinese). Chin J Prac Inter Med. 2009;29:354-7.

80. Wen FQ, Shen YC. Expectorant therapy revisited in chronic obstructive pulmonary disease (Chinese). Zhonghua Jie He He Hu Xi Za Zhi. 2011; 34:243-5

81. Chinese chronic disease prevention and treatment plan (2012-2015). http:/ / www.moh.gov.cn/zhuzhan/wsbmgz/201304/b8de7b7415ca4996b3567e5a 09e43300.shtml. Accessed September 1, 2016.

82. Chinese Associattion on Tobacco Control. http://www.catcprc.org.cn/in dex.aspx?menuid=4\&type $=$ articleinfo\&lanmuid $=104 \&$ infoid $=7557 \&$ langua ge $=$ cn\# Accessed September 26, 2016.

83. National health and Family Planning Commission of the People's Republic of China. Guideline on China clinical smoking cessation (2015) (Chinese) Chinese Journal of Health Management. 2016;10:88-95

84. Zhou Y, Zou Y, Li X et al. Lung function and incidence of chronic obstructive pulmonary disease after improved cooking fuels and kitchen ventilation: a 9-year prospective cohort study. PloS Med. 2014;11(3):e1001621.

85. http:/ / health.people.com.cn/n1/2016/0201/c398004-28101157.html. Accessed September 1, 2016.

86. National Science and Technology Information System. http://service.most gov.cn/2015tztg_all/20160625/1127.html. Accessed September 1, 2016. 